\title{
Social support and HIV/STDs infections among a probability-based sample of rural married migrant women in Shandong Province, China
}

\author{
Wenkang Ma' ${ }^{1}$, Dianmin Kang${ }^{2}$, Yapei Song ${ }^{3}$, Chongyi Wei ${ }^{4}$, Gifty Marley ${ }^{1}$ and Wei Ma ${ }^{1 *}$
}

\begin{abstract}
Background: The increasing population of marriage-based migrant women is disproportionally affected by AIDS/ STDs in China, and social support plays a critical role. This study aims to describe the social support level received by married migrant women in rural areas in Shandong province in comparison to non-migrant local women, identifies the relevant factors of this social support condition among married migrant women, and observes the correlation between social support level and infection status of AIDS and STDs among this group.

Methods: A probability-based sample of 1,076 migrant and 1,195 local women were included in the study. A pre-tested field questionnaire was administered to participants through a direct face-to-face interview. Questionnaire contained questions on socio-demographic information, AIDS and STDs prevalence information and Social Support Rating Scale (SSRS) which measures objective support, subjective support, and utilization of social support.

Results: Compared to local women, married migrant women had lower levels of social support in most dimensions. Multi-variable analysis revealed that relationship with spouse, family average income, number of children, education, engagement and claimed reasons of moving have various correlations with one or all dimensions of social support scores. Higher social support is also related to awareness of infection status of HIV and STDs among this group.

Conclusion: Our findings provide further evidence that married migrant women have lower levels of social support which may be related to some social characteristics and their awareness status of AIDS and STDs infection status and that targeted interventions need to be developed for this population.
\end{abstract}

Keywords: HIV/AIDS, Migrant women, Social support, China

\section{Background}

Migrants are broadly defined as people who move from one place to another temporarily, seasonally or permanently for a range of voluntary and/or involuntary reasons [1]. They play a critical role in the dynamics of infectious diseases like HIV [2-4]. Migration can have negative impact on mental health, making immigrants more

\footnotetext{
* Correspondence: weima@sdu.edu.cn

'Department of Epidemiology and Health Statistics, School of Public Health Shandong University, 44 West Wenhua Road, Jinan, Shandong Province 250012, China

Full list of author information is available at the end of the article
}

vulnerable to mental health problem such as depression [5], which may increase risk behaviors associated with diseases such as HIV/AIDS. Moreover, migrants often have difficulty maintaining their health because of limited access to local healthcare as well as defective official supervision in host area $[6,7]$. As a result, migrant populations can be disproportionately affected by certain disease outbreaks.

In 2011, it was estimated that approximately 780,000 people were living with HIV/AIDS in China. One of the characteristics of the HIV epidemic in China is that some sub-populations, such as migrant women, are

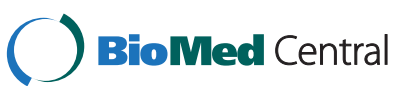

(c) 2015 Ma et al. Open Access This article is distributed under the terms of the Creative Commons Attribution 4.0 International License (http://creativecommons.org/licenses/by/4.0/), which permits unrestricted use, distribution, and reproduction in any medium, provided you give appropriate credit to the original author(s) and the source, provide a link to the Creative Commons license, and indicate if changes were made. The Creative Commons Public Domain Dedication waiver (http://creativecommons.org/publicdomain/zero/1.0/) applies to the data made available in this article, unless otherwise stated. 
disproportionately affected [8]. In 2009, $20 \%$ of the 2,660 HIV/AIDS cases reported in Shandong province were among migrant women [9]. Due to a high male-tofemale sex ratio and a growing gap in poverty, poor rural men who cannot afford to marry local women in their provinces seek to marry women from even poorer regions. These women usually come from poverty-stricken rural ethnic areas in Southwest China (such as Yunnan province, Guizhou province, and Sichuan province) and bordering countries (such as Burma and Vietnam) where HIV prevalence is higher and concentrated among key populations such as people who inject drugs [10, 11]. Epidemiological surveys found that HIV prevalence among these married rural migrant women in Shandong province was $0.65 \%$ in 2008 [11], which is much higher than that among the general population in the province (range 0.01-0.09\%) [12, 13]. Among those who were HIV-positive, 20.4\% had an HIV-infected spouse and the rate of mother-to-child transmission was high (13.7\%) [11]. This high rate of mother-to-child suggested that HIV testing was not routinely conducted with pregnant migrant women; and hence a significant proportion of them may not be aware of their HIV status, which place their spouses and sexual partners at greater risk for infection [9].

It is hypothesized that factors such as demographic characteristics, an individual's cultural competence [14], perceived discrimination [15] and acculturative stress $[16,17]$ interact with each other to affect psychological health among migrants. Among the many aspects of psychological health, social support plays a critical role and is an important indicator of migrants' psychological well-being. Social support as a broad term normally refers to the perception and actuality that one is being cared for and has assistance available to him or her from other people [18]. It has been found to have positive effects on migrants' health status as well as to enhance their utilization of health care services. For example, social therapeutic network, which utilized social network for health promotion, has been reported to benefit migrant women in pregnancy [19], and inadequate social support has been noted as a risk factor for poorer utilization of maternity services [20].

As such, availability of adequate social support or the lack of it may affect HIV risks among married migrant women in rural China. Despite the fact that migrant women bear a higher burden of HIV/AIDS compared to the general population in China, few studies have documented the social support profiles of this group. One descriptive study using cluster sampling reported lower levels of social support among these women compared to that among their local counterpart in a county in Shandong province [21]. As the number of women migrating to rural areas for marriage purposes is likely to increase $[9,10,22]$, it is therefore important to examine levels of social support and associated risk factors among this population on wider scales and from representative samples so that appropriate intervention measures can be implemented to reduce HIV infections among these women and their spouses and sexual partners, as well as to improve their psychological well-being. Using a probability-based sample of married women from Shandong province, this paper describes levels of social support among rural migrant women in comparison to non-migrant local women, and identifies factors influencing social support among this group. It also investigates the correlation between levels of different social support dimensions and awareness of AIDS and STDs infection.

\section{Methods}

\section{Participants recruitment}

To increase diversity of participants (i.e., geographic distribution), three cities in Shandong Province, Yantai, Weifang, and Linyi, were selected to recruit participants. Yantai, Weifang and Linyi are located in the eastern, central and southern parts of the province, respectively. Two counties in each city and two towns in each of these counties were then randomly selected as study sites. Migrant and local non-migrant women were recruited using cluster sampling with migrant women being mostly scattered in different villages. Because there is no household registration or record of migrant women, nor are there any distribution patterns of these women, we recruited participants using the official checkup system. The township governments in Shandong Province provide free health checkups for women of child-bearing age at least once a year, hence for sampling efficiency participants were recruited from the population of women who attended the medical checkups. For the purpose of our study, we made several restrictions in our participant selection. First, we selected from women from areas with high HIV prevalence in southwest China (Yunnan province, Guizhou province, and Sichuan province) and bordering countries (Burma and Vietnam), because these places are the main sources of rural migrant women in Shandong $[10,11]$, and that in this way we can better assess the possible relationship between social support and HIV/STDs infection status. According to a report in 2011, $90 \%$ of the HIV/AIDS patients in rural Shandong area had the age of 20-39 years old [9]. Thus, we chose participants from women who migrated to Shandong after the year 1990.

A total of 1,300 married migrant women qualified to partake in the study out of which 1,164 of them completed the interview (response rate of $89.5 \%$ ). Inclusion criteria for migrant women included: (1) was originally from a province or a foreign country with higher HIV 
prevalence such as Yunnan province, Guangxi province, Guizhou province, Sichuan province [8], Burma and Vietnam; (2) migrated to Shandong province after 1990, and was married to or cohabiting with a rural man in Shandong province, and (3) aged between 18-50. Inclusion criteria for non-migrant women included: (1) originally from Shandong province, (2) married, and (3) aged between 18-50. The Ethics Review Committee (ERC) of Public Health at the Shandong University has reviewed and approved the proposed use of human subjects in this research project.

\section{Data collection}

After obtaining verbal informed consent from participants, face-to-face interviewer-administered survey interviews were conducted by trained female interviewers between September 2012 and January 2013. Socio-demographic characteristics, HIV related behaviors and social support information were collected. Socio-demographic information included current address, age, educational level, ethnicity, marriage history (first-married vs. remarried), annual income per capita in the household, quality of relationship with spouse, living arrangement (not living with family vs. living with family), total number of children during lifetime and that with current spouse, occupation, and time since migrating to Shandong Province. HIV-related behaviors included history of blood transfusion, premarital sex, extramarital sex, sexually transmitted diseases, drug use and HIV testing. Information on HIV and STDs infection was collected through questions as: Are you infected with HIV? a. Yes, b. No, c. I don't know. Have you been diagnosed STD? a. Yes, b. No.

Social support was measured using the Social Support Rate Scale (SSRS), which has demonstrated good reliability among Chinese populations [23, 24]. SSRS is a 10-item scale measuring 3 dimensions of social support: subjective support (4 items), objective support (3 items), and utilization of social support (3 items). Questions on subjective support include questions such as: How many friends do you have who can provide help and support to you? a. none, b. 1-2, c. 3-5, d. 6 and more. Questions on objective support include: What have been your sources of economic and practical support in case of emergency? (1) no sources; (2) the following sources (multiple choice): a. spouse, b. other family members, c. relatives, e. colleagues, f. employer/company, g. official or semi-official bodies (e.g. political parties, or a labor union) h. unofficial bodies (e.g. religious groups, social groups or other social organizations), i. others (please identify). Questions on utilization of social support include: How do you seek for help when you are in trouble? (1) depending on my own and turning to no one, (2) seldom turning to others for help, (3) sometimes seeking help from others, (4) turning to families, relatives and some organizations. Scores are calculated and appraised on three dimensions as well as on a whole. The possible total score of SSRS ranges from 11 to 66 points. A higher score indicates greater social support. Cronbach's alpha is 0.732 for the entire sample, and 0.707 and 0.741 for migrant women and local women, respectively.

\section{Data analysis}

Responses with missing data were identified as invalid and excluded; and the analysis contained valid responses from 1,076 married migrant women and 1,195 local non-migrant women (the proportion of missing data was $\leq 25 \%$ ). Data were double entered with Epidata 3.1 and analyzed using SAS 9.1. Chi-square tests were conducted to compare socio-demographic characteristics between married migrant women and non-migrant women. Levels of social support between married migrant women and non-migrant women were compared using student $t$ test. One-way analysis of variance (One-Way ANOVA) and multi-way analysis of variance (multi-way ANOVA) were conducted to identify factors significantly associated with receipt of social support, and dimensions of social support related to infection of AIDS and STDs among migrant women.

\section{Results}

\section{Characteristics of participants}

There were no significant differences between nonmigrant women and migrant women by location of residency, age, perceived relationship quality with spouse and total number of children during lifetime (Table 1). However, migrant women were more likely to be illiterate to be ethnic minorities, and to report lower annual income per capita in the household compared to non-migrant women $(P S<0.001)$. Migrant women had significantly fewer children with their current husbands, not living together with their husbands' families, and were more likely to report that their current marriage was not their first marriage compared to non-migrant women $(P s<0.001)$.

\section{Social support}

The means and standard deviations of social support score received by migrant and non-migrant women are detailed and compared in Table 2. In most aspects immigrant group recorded a lower score, except that the dimension of utilization of support the difference was not statistically significant.

Factors associated with social support, and the relation of AIDS and STDs infection to social support among migrant women

\section{One-way ANOVA}

Corrected means of social support scores were first tested by one-way analysis of variance (One-Way 
Table 1 Comparison of characteristics between non-migrant women $(N=1,195)$ and migrant women $(N=1,076)$ from rural area of Shandong Province, China

\begin{tabular}{|c|c|c|c|c|}
\hline & Local women $(n=1,195)$ & Migrant women $(n=1,076)$ & $x^{2}$ & $P$ \\
\hline & $n^{\mathrm{a}}$ & $n^{a}$ & & \\
\hline Current address & & & & \\
\hline Yantai & $379(31.7 \%)$ & $350(32.5 \%)$ & 3.304 & 0.192 \\
\hline Linyi & $397(33.2 \%)$ & $386(35.9 \%)$ & & \\
\hline Weifang & $419(35.1 \%)$ & $340(31.6 \%)$ & & \\
\hline Age (year) & & & & \\
\hline$<30$ & $251(21.6 \%)$ & $245(23.0 \%)$ & 0.671 & 0.715 \\
\hline $30-39$ & $556(47.8 \%)$ & $499(46.9 \%)$ & & \\
\hline$\geq 40$ & $355(30.6 \%)$ & $319(30.2 \%)$ & & \\
\hline Education level & & & & \\
\hline Illiterate & $23(2.0 \%)$ & $198(19.0 \%)$ & 434.648 & $<0.001$ \\
\hline Elementary school & $238(20.5 \%)$ & $464(44.5 \%)$ & & \\
\hline Junior middle school & $713(61.5 \%)$ & $343(32.9 \%)$ & & \\
\hline Senior meddle school or above & $185(16.0 \%)$ & $37(3.6 \%)$ & & \\
\hline Ethinicity & & & & \\
\hline Han Chinese & $1130(99.2 \%)$ & $533(52.0 \%)$ & 675.834 & $<0.001$ \\
\hline Ethnic minorities & $9(0.8 \%)$ & $492(48.0 \%)$ & & \\
\hline Marriage history & & & & \\
\hline First marriage & $1085(97.3 \%)$ & $833(84.3 \%)$ & 110.302 & $<0.001$ \\
\hline Remarried & $30(2.7 \%)$ & $155(15.7 \%)$ & & \\
\hline Annual income per capita in the house & & & & \\
\hline$<5,000$ & $236(20.1 \%)$ & $340(32.9 \%)$ & 70.902 & $<0.001$ \\
\hline $5,000-$ & $338(28.7 \%)$ & $328(31.7 \%)$ & & \\
\hline $10000-$ & $245(20.8 \%)$ & $170(16.4 \%)$ & & \\
\hline $15000-$ & $358(30.4 \%)$ & $196(19.0 \%)$ & & \\
\hline Quality of relationship with spouse & & & & \\
\hline Poor & $62(5.2 \%)$ & $42(3.9 \%)$ & 2.410 & 0.300 \\
\hline Average & $566(47.6 \%)$ & $528(49.3 \%)$ & & \\
\hline Good & $562(47.2 \%)$ & $501(46.8 \%)$ & & \\
\hline Living situation & & & & \\
\hline Not living with the husband's family & $31(2.6 \%)$ & $115(10.7 \%)$ & 61.804 & $<0.001$ \\
\hline Living with the husband's family & $1160(97.4 \%)$ & $956(89.3 \%)$ & & \\
\hline Number of children & & & & \\
\hline 0 & $25(2.1 \%)$ & $37(3.6 \%)$ & & \\
\hline 1 & $698(59.7 \%)$ & $631(61.3 \%)$ & 5.669 & 0.059 \\
\hline$\geq 2$ & $446(38.2 \%)$ & $362(35.1 \%)$ & & \\
\hline Number of offspring with current husb & & & & \\
\hline 0 & $26(2.2 \%)$ & $56(5.5 \%)$ & 34.453 & $<0.001$ \\
\hline 1 & $704(60.5 \%)$ & $684(66.9 \%)$ & & \\
\hline$\geqq 2$ & $434(37.3 \%)$ & $282(27.6 \%)$ & & \\
\hline
\end{tabular}

${ }^{a}$ Missing exists if the sum of $\mathrm{n}$ is less than $\mathrm{N} ;{ }^{\mathrm{b}}$ CNY: Chinese Yuan; $6.1 \mathrm{CNY}=1$ USD 
Table 2 Comparison of levels of social support between migrant women $(N=1,195)$ and non- migrant women $(N=1.076)$ from rural area of Shandong Province, China

\begin{tabular}{|c|c|c|c|c|}
\hline & Migrant women $(x \pm s)$ & Local women $(x \pm s)$ & $t$ & $P$ \\
\hline Subjective support & $25.00 \pm 4.54$ & $26.55 \pm 4.12$ & -8.453 & $<0.001$ \\
\hline $\begin{array}{l}\text { How many friends do you have who can provide help and } \\
\text { support to you? }\end{array}$ & $2.74 \pm 0.86$ & $2.88 \pm 0.86$ & -4.006 & $<0.001$ \\
\hline How is your relationship with your neighbors? & $3.16 \pm 0.94$ & $3.34 \pm 0.90$ & -4.669 & $<0.001$ \\
\hline How is your relationship with your colleagues? & $3.13 \pm 0.91$ & $3.33 \pm 0.88$ & -5.575 & $<0.001$ \\
\hline How is the support you receive from your family members? & $15.98 \pm 3.58$ & $16.99 \pm 3.10$ & -7.148 & $<0.001$ \\
\hline Objective support & $7.50 \pm 2.27$ & $8.05 \pm 2.64$ & -5.345 & $<0.001$ \\
\hline What was your living condition in the past year? & $3.76 \pm 0.73$ & $3.94 \pm 0.36$ & -7.618 & $<0.001$ \\
\hline $\begin{array}{l}\text { What have been your sources of economic and practical support } \\
\text { in case of emergency? }\end{array}$ & $1.77 \pm 1.03$ & $1.97 \pm 1.31$ & -4.222 & $<0.001$ \\
\hline What have been your sources of care when you were in trouble? & $1.97 \pm 1.14$ & $2.13 \pm 1.40$ & -2.917 & 0.004 \\
\hline Utilization of support & $8.11 \pm 1.80$ & $8.22 \pm 1.56$ & -1.457 & 0.145 \\
\hline What is your way of confiding when you are in trouble? & $3.42 \pm 0.79$ & $3.52 \pm 0.72$ & -3.108 & 0.002 \\
\hline How do you seek for help when you are in trouble? & $2.86 \pm 1.01$ & $2.99 \pm 0.99$ & -3.146 & 0.002 \\
\hline $\begin{array}{l}\text { To what extent are you involved in group (e.g. political organizations, } \\
\text { religious organizations, labor unions and student unions) activities? }\end{array}$ & $1.84 \pm 1.04$ & $1.71 \pm 0.76$ & 3.322 & 0.001 \\
\hline Total points of social support & $40.61 \pm 6.19$ & $42.81 \pm 6.29$ & -8.383 & $<0.001$ \\
\hline
\end{tabular}

ANOVA) (Table 3). Family average income was found to correlate with every score dimension, namely subjective support $(P<0.001)$, objective support $(P=0.001)$, utilization of support $(P<0.001)$ and total score $(P<0.001)$. Several factors were found to possibly influence one or all dimensions of social support scores received, including education status, family average income, years living in Shandong Province, job engaged, relationship with current husband, the number of offspring with current husband and reason for marrying in Shandong.

Corrected means of social support scores were also tested by one-way analysis of variance (One-Way ANOVA) with their self-reported prevalence of AIDS/HIV and sexually transmitted diseases (STDs) (Table 4). Women diagnosed with STDs received lower utilization of support score $(P=0.0029)$ and lower total score $(P=0.0171)$. Compared with the women who did not know their AIDS infectious status, women knowing they were not infected received higher scores in subjective support $(P=0.0304)$, utilization of support $(P=0.032)$ and total score $(P=0.0137)$.

\section{Multi-way ANOVA}

Relevant factors of social support scores selected from One-way ANOVA were then analyzed with multi-way analysis of variance (multi-way ANOVA), the correlations of scores to self-reported AIDS and STDs infection were also included. Those possible relevant factors were examined respectively for independent effect. According to the result obtained, several factors were found to correlate with different dimensions of social support score. (Table 5).

Relationship with spouse was positively correlated with scores of all dimensions $(P s<0.001)$. Migrant women with better relationship with their husband recorded higher scores on subjective and objective support as well as on total score. Moreover, for women with better spousal relationship (medium and good group), utilization of support tended to descend as relationship condition ascends.

Family average income was also found to correlate with all dimensions of scoring. Higher income indicated higher score on support utilization $(P<0.001)$. Migrant women with annual income per capita less than 5000 CNY (the <5000 group) had the lowest subjective support and the 5000-9999 group had the highest one. For the objective support and the total score, the $<5000$ group scored the lowest while the 10000-14999 group scored the highest. In addition, a positive correlation existed between number of children with current spouse and subjective support as well as total score of support with $P$-values of 0.001 , and 0.050 respectively. With higher education, utilization of support score rose significantly $(P=0.006)$. Besides, migrant women engaged in agricultural activities and services received higher scores in subjective support dimension than women with other jobs, while receiving lower scores in utility of support dimension.

When it came to reason for immigration to Shandong among the migrant women, devotion graded higher in objective and utilization part as well as in total score than those holding living condition reasons or other 
Table 3 Possible influence factors for social support score- one-way ANOVA

\begin{tabular}{|c|c|c|c|c|c|c|c|c|c|c|c|c|}
\hline & \multicolumn{3}{|c|}{ Subjective support } & \multicolumn{3}{|c|}{ Objective support } & \multicolumn{3}{|c|}{ Utilization of support } & \multicolumn{3}{|l|}{ Total score } \\
\hline & Mean \pm SD & $\mathrm{F} / \mathrm{t}$ & $P$ & Mean \pm SD & $F / t$ & $P$ & Mean \pm SD & $F / t$ & $P$ & Mean \pm SD & $\mathrm{F} / \mathrm{t}$ & $P$ \\
\hline \multicolumn{13}{|l|}{ Education level } \\
\hline Illiterate ${ }^{a}$ & $24.83 \pm 5.08$ & 3.216 & 0.041 & $7.16 \pm 2.15$ & 4.318 & 0.014 & $7.70 \pm 1.63$ & 19.830 & $<0.001$ & $36.69 \pm 6.29$ & 2.957 & 0.052 \\
\hline Elementary school & $25.38 \pm 4.59$ & & & $7.48 \pm 2.30$ & & & $7.97 \pm 1.83$ & & & $40.82 \pm 6.48^{b}$ & & \\
\hline $\begin{array}{l}\text { Junior middle school and } \\
\text { above }\end{array}$ & $24.60 \pm 4.06$ & & & $7.74 \pm 2.26^{c}$ & & & $8.57 \pm 1.76^{c}$ & & & $40.91 \pm 5.50^{b}$ & & \\
\hline \multicolumn{13}{|l|}{$\begin{array}{l}\text { Annual income per capita in } \\
\text { the household }\left(C N Y^{d}\right)\end{array}$} \\
\hline$<5000^{\mathrm{a}}$ & $24.25 \pm 5.27$ & 9.254 & $<0.001$ & $7.21 \pm 2.39$ & 6.324 & $<0.001$ & $7.49 \pm 1.69$ & 38.806 & $<0.001$ & $38.95 \pm 7.03$ & 14.046 & $<0.001$ \\
\hline $5000-$ & $25.93 \pm 4.62^{c}$ & & & $7.74 \pm 2.15^{c}$ & & & $7.98 \pm 1.69^{c}$ & & & $41.65 \pm 6.24^{c}$ & & \\
\hline $10000-$ & $25.44 \pm 3.59^{c}$ & & & $8.04 \pm 2.03^{c}$ & & & $8.34 \pm 1.76^{c}$ & & & $41.81 \pm 4.94^{c}$ & & \\
\hline $15000-$ & $24.42 \pm 3.69$ & & & $7.61 \pm 2.08^{b}$ & & & $9.10 \pm 1.67^{c}$ & & & $41.13 \pm 5.14^{c}$ & & \\
\hline \multicolumn{13}{|l|}{ Years in Shandong } \\
\hline$<5^{\mathrm{a}}$ & $24.83 \pm 3.79$ & 0.973 & 0.405 & $7.40 \pm 2.17$ & 0.356 & 0.785 & $8.47 \pm 1.80$ & 4.695 & 0.003 & $40.69 \pm 5.22$ & 0.079 & 0.971 \\
\hline $5-$ & $25.05 \pm 4.21$ & & & $7.55 \pm 2.20$ & & & $8.16 \pm 1.80$ & & & $40.76 \pm 5.68$ & & \\
\hline $10-$ & $24.90 \pm 4.84$ & & & $7.61 \pm 2.34$ & & & $8.06 \pm 1.78^{b}$ & & & $40.57 \pm 6.64$ & & \\
\hline $15-$ & $25.44 \pm 4.94$ & & & $7.50 \pm 2.34$ & & & $8.13 \pm 1.80^{c}$ & & & $40.72 \pm 6.74$ & & \\
\hline \multicolumn{13}{|l|}{ Job engaged } \\
\hline Farming & $25.24 \pm 4.57$ & 4.893 & $<0.001$ & $7.54 \pm 2.28$ & 0.240 & 0.811 & $8.01 \pm 1.78$ & -5.864 & $<0.001$ & $40.80 \pm 6.23$ & 1.516 & 0.131 \\
\hline Others & $23.55 \pm 3.60$ & & & $7.49 \pm 2.29$ & & & $8.97 \pm 1.73$ & & & $40.01 \pm 5.49$ & & \\
\hline \multicolumn{13}{|c|}{ Quality of relationship with spouse } \\
\hline Poor $^{a}$ & $21.50 \pm 5.61$ & 29.642 & $<0.001$ & $5.31 \pm 2.44$ & 21.837 & $<0.001$ & $7.81 \pm 2.06$ & 8.253 & $<0.001$ & $34.62 \pm 7.35$ & 26.761 & $<0.001$ \\
\hline Average & $24.39 \pm 4.33^{c}$ & & & $7.56 \pm 2.10^{c}$ & & & $8.34 \pm 1.81$ & & & $40.28 \pm 5.97^{c}$ & & \\
\hline Good & $25.95 \pm 4.44^{c}$ & & & $7.65 \pm 2.31^{c}$ & & & $7.90 \pm 1.74$ & & & $41.50 \pm 6.02^{c}$ & & \\
\hline \multicolumn{13}{|c|}{ Number of offspring with husband } \\
\hline $0^{a}$ & $22.82 \pm 4.37$ & 13.346 & $<0.001$ & $6.80 \pm 2.65$ & 2.864 & 0.057 & $8.95 \pm 1.79$ & 12.125 & $<0.001$ & $38.57 \pm 5.91$ & 4.777 & 0.009 \\
\hline 1 & $24.68 \pm 4.60^{c}$ & & & $7.49 \pm 2.25^{b}$ & & & $8.19 \pm 1.82^{c}$ & & & $40.37 \pm 6.36^{b}$ & & \\
\hline$\geq 2$ & $25.87 \pm 4.29^{c}$ & & & $7.59 \pm 2.15^{b}$ & & & $7.76 \pm 1.73^{c}$ & & & $41.22 \pm 5.82^{c}$ & & \\
\hline \multicolumn{13}{|c|}{ Reason of marrying in Shandong } \\
\hline Good living condition & $25.01 \pm 4.67$ & 3.739 & 0.024 & $7.54 \pm 2.14^{c}$ & 11.003 & $<0.001$ & $8.03 \pm 1.77$ & 4.499 & 0.011 & $40.58 \pm 6.06^{c}$ & 9.612 & $<0.001$ \\
\hline Devotion to husband & $25.47 \pm 4.31^{c}$ & & & $7.79 \pm 2.38^{c}$ & & & $8.38 \pm 1.75^{b}$ & & & $41.65 \pm 6.17^{c}$ & & \\
\hline Others ${ }^{a}$ & $24.30 \pm 4.35$ & & & $6.80 \pm 2.31$ & & & $8.00 \pm 1.90$ & & & $39.10 \pm 6.25$ & & \\
\hline
\end{tabular}

${ }^{a}$ control group; ${ }^{b}$ compared with control group $P \leqq 0.05$

compared with control group $P<0.01 ;{ }^{d}$ CNY: Chinese Yuan; $6.1 \mathrm{CNY}=1$ USD 
Table 4 Possible relation of AIDS and STDs infection to social support score- one-way ANOVA

\begin{tabular}{|c|c|c|c|c|c|c|c|c|c|c|c|c|}
\hline & \multicolumn{3}{|c|}{ Subjective support } & \multicolumn{3}{|c|}{ Objective support } & \multicolumn{3}{|c|}{ Utilization of support } & \multicolumn{3}{|l|}{ Total score } \\
\hline & Mean $\pm S D$ & $F / t$ & $P$ & Mean \pm SD & $F / t$ & $P$ & Mean \pm SD & $F / t$ & $P$ & Mean \pm SD & $F / t$ & $P$ \\
\hline \multicolumn{13}{|c|}{ Are you infected with AIDS } \\
\hline Yes & $27.67 \pm 3.67$ & 3.504 & 0.030 & $6.83 \pm 2.79$ & 0.887 & 0.412 & $8.83 \pm 2.48$ & 3.455 & 0.032 & $43.33 \pm 5.13$ & 4.308 & 0.014 \\
\hline No & $25.11 \pm 4.46^{b}$ & & & $7.55 \pm 2.24$ & & & $8.17 \pm 1.80^{b}$ & & & $40.83 \pm 6.06^{b}$ & & \\
\hline Don't know ${ }^{a}$ & $24.27 \pm 4.91$ & & & $7.34 \pm 2.26$ & & & $7.80 \pm 1.66$ & & & $39.41 \pm 6.80$ & & \\
\hline \multicolumn{13}{|c|}{ Have you been diagnosed STDs } \\
\hline Yes & $23.83 \pm 4.70$ & 3.608 & 0.058 & $7.37 \pm 1.99$ & 0.138 & 0.710 & $7.42 \pm 1.49$ & 8.899 & 0.003 & $38.62 \pm 6.25$ & 5.700 & 0.017 \\
\hline No & $25.04 \pm 4.52$ & & & $7.50 \pm 2.27$ & & & $8.16 \pm 1.80$ & & & $40.71 \pm 6.19$ & & \\
\hline
\end{tabular}

a control group

compared with control group $P \leqq 0.05$ 
Table 5 Factors related to dimensions of social support- multi-way ANOVA

\begin{tabular}{|c|c|c|c|c|c|c|c|c|c|c|}
\hline \multirow[t]{2}{*}{ Source } & \multicolumn{5}{|l|}{ Subjective support } & \multicolumn{5}{|l|}{ Objective support } \\
\hline & Type III Sum of Squares & df & Mean Square & $F$ & $P$ & Type III Sum of Squares & df & Mean Square & $F$ & $P$ \\
\hline Corrected Model & 2340.803 & 18 & 130.045 & 7.385 & $<0.001$ & 313.105 & 18 & 17.395 & 3.955 & $<0.001$ \\
\hline Intercept & 17203.945 & 1 & 17203.945 & 976.997 & $<0.001$ & 1408.332 & 1 & 1408.332 & 320.217 & $<0.001$ \\
\hline Education level & 27.728 & 2 & 13.864 & 0.787 & 0.455 & 12.310 & 2 & 6.155 & 1.399 & 0.247 \\
\hline Income & 479.938 & 3 & 159.979 & 9.085 & $<0.001$ & 83.290 & 3 & 27.763 & 6.313 & $<0.001$ \\
\hline Job & 112.470 & 1 & 112.470 & 6.387 & 0.012 & 1.647 & 1 & 1.647 & 0.374 & 0.541 \\
\hline Quality of relationship with spouse & 778.727 & 2 & 389.363 & 22.112 & $<0.001$ & 128.968 & 2 & 64.484 & 14.662 & $<0.001$ \\
\hline Number of children with husband & 264.589 & 2 & 132.294 & 7.513 & 0.001 & 3.249 & 2 & 1.624 & 0.369 & 0.691 \\
\hline Reason of marrying in Shandong & 84.064 & 2 & 42.032 & 2.387 & 0.093 & 33.980 & 2 & 16.990 & 3.863 & 0.021 \\
\hline Years living in Shandong & 16.437 & 3 & 5.479 & 0.311 & 0.817 & 2.370 & 3 & 0.790 & 0.180 & 0.910 \\
\hline Are you infected with AIDS & 183.720 & 2 & 91.860 & 5.217 & 0.006 & 1.554 & 2 & 0.777 & 0.177 & 0.838 \\
\hline Have you been diagnosed STDs & 30.309 & 1 & 30.309 & 1.721 & 0.190 & 0.005 & 1 & 0.005 & 0.001 & 0.973 \\
\hline \multirow[t]{2}{*}{ Source } & \multicolumn{5}{|l|}{ Utility of support } & \multicolumn{5}{|c|}{ Total score of social support } \\
\hline & Type III Sum of Squares & df & Mean Square & $F$ & $P$ & Type III Sum of Squares & df & Mean Square & F & $P$ \\
\hline Corrected Model & 497.359 & 18 & 27.631 & 10.174 & $<0.001$ & 4541.345 & 18 & 252.297 & 7.775 & $<0.001$ \\
\hline Intercept & 2098.429 & 1 & 2098.429 & 772.68 & $<0.001$ & 46010.323 & 1 & 46010.323 & 1417.886 & $<0.001$ \\
\hline Education level & 28.237 & 2 & 14.118 & 5.199 & 0.006 & 72.460 & 2 & 36.230 & 1.116 & 0.328 \\
\hline Income & 136.079 & 3 & 45,360 & 16.702 & $<0.001$ & 1444.949 & 3 & 481.650 & 14.843 & $<0.001$ \\
\hline Job & 12.552 & 1 & 12.552 & 4.622 & 0.032 & 69.650 & 1 & 69.650 & 2.146 & 0.143 \\
\hline Quality of relationship with spouse & 44.151 & 2 & 22.076 & 8.129 & $<0.001$ & 1411.830 & 2 & 705.915 & 21.754 & $<0.001$ \\
\hline Number of children with husband & 13.839 & 2 & 6.920 & 2.548 & 0.079 & 194.533 & 2 & 97.266 & 2.997 & 0.050 \\
\hline Reason of marrying in Shandong & 21.933 & 2 & 10.967 & 4.038 & 0.018 & 365.918 & 2 & 182.959 & 5.638 & 0.004 \\
\hline Years living in Shandong & 2.284 & 3 & 0.761 & 0.280 & 0.840 & 19.353 & 3 & 6.451 & 0.199 & 0.897 \\
\hline Are you infected with AIDS & 13.488 & 2 & 6.744 & 2.483 & 0.084 & 306.878 & 2 & 153.439 & 4.728 & 0.009 \\
\hline Have you been diagnosed STDs & 33.466 & 1 & 33.466 & 12.323 & $<0.001$ & 125.854 & 1 & 125.854 & 3.878 & 0.049 \\
\hline
\end{tabular}


reasons. However, years of living in Shandong recorded no statistical significance in relation to social support scores in all dimensions.

As for AIDS and STDs infection status, it is found that infection of AIDS was correlated with subjective support $(P=0.006)$ and infection status of STDs with utility of support score $(P<0.001)$, while they both had a correlation with total score of social support with $P$-values of 0.009 and 0.049 respectively.

\section{Discussion}

This paper examined the social support condition among a probability-based sample of rural married migrant women and local non-migrant women in Shandong province, China. Compared to their local non-migrant counterparts, migrant women recorded lower scores of social support in almost all dimensions. This finding corresponds with past studies on migrant groups in China [25, 26]. It also confirms the results of one of the few social support study focused on Chinese migrant women [21].

The finding that migrant women had less social support is understandable. Their migration is one from underdeveloped remote areas even less-developed countries to a coastal developed province, thus correlates with many stressors such as language barriers, cultural conflicts, ethnic discrimination, change in social network and lack of support systems, which have been identified as influencing factors of social support for immigrants. Besides, as a special group in the migrant population, migrant women are separated from family and friends, depend more on their current husband and have few links with the new community [27]. This may intensify their weakness in social support network. Considering that their primary reasons for migration are marriage and pursuit of a better life, this is especially true. Migrant women also face special gender-related socioeconomic and physiological problems. Prenatal and postpartum problems are noted among them [28-30]. Stress factors in life as acculturation and adaption may intensify these problems. Thus, they are more susceptible to physical and mental health problem than local women.

However, there are also reports that migrant populations have a higher support level than local groups, arguing that immigration enables people to obtain better job and better socioeconomic status, thus acting positively on them [31, 32]. However, although migrant women have risen in socioeconomic status in our scenario, this theory does not apply. Compared with the widelyfocused-on immigrants group (e.g., immigrant workers and merchants) whose migrating destination are developed districts, women in this study have several characteristics which may explain their worse social support conditions: (1) possible ethnic and language barriers makes them unable to smoothly adapt to new communities or pursue better socioeconomic status; (2) their origin and special way of migration (marriage) makes them susceptible to discrimination and hinders them from merging into new local societies, and additionally the conservative atmosphere in rural areas may intensify this discrimination; (3) low socioeconomic status of their husbands in local communities weakens their relative affection and living content.

This study is also the first to appraise common life factors as relevant factors of social support condition among married migrant women. One of the most important factors identified is relationship with spouse. Better relationship is related with higher scores in all dimensions of support, which agrees with the conclusions that family plays a critical role in the mental health of female participants [33] and that immigrant women rely more on their husband [28]. Better relationship indicates more support from spouse and family, which helps immigrants diminish acculturative stress and perceived discrimination during migration and adaptation [34]. However, this study also found that utilization of support declines on a higher level of subjective support score. This may because women with better relationship with spouse feel more content and positive, thus less motivated to seek and utilize more social support. It is also noted that women who have more children with their present spouses scored higher in subjective support and the total score. As children serve as the bond of family members, they can influence the relationship with spouse greatly as well as play a big role in the mothers' mental health.

Additionally, higher family average income correlates with higher support scores in a certain range, since higher economic level satisfies the family's material needs better and can provide the family with better social status. Higher education level is related with better utility of social support, possibly because better education indicates better adaptation and self-adjustment. On reasons of moving to Shandong, women claiming devotion had higher grades in objective and utilization part as well as in total score than those holding other reasons. This may because those claiming devotion as the reason are more willing to adapt to new environment and seek for help when necessary.

Number of years living in Shandong however showed no significant relation with social support scores in any dimensions, although it had been expected that as immigrants live longer in the move-in place, their social support develops because of better adaptation, as well as their mental health status.

It has been reported that married migrant women were more likely to have HIV-related behaviors (i.e., blood transfusion, premarital sex, extramarital sex, sexually transmitted diseases and drug use), and less likely to have an HIV test [35]. We find that higher total social 
support score is related to better awareness of AIDS/ STD infection. This finding coheres with the theories that social support as a critical part in psychological health has positive effects on migrants' health status as well as enhances their utilization of health care services. Migrant women with better social support may carry out less health risk behaviors such as extramarital sex and drug use. They also make better use of health care resources so that their AIDS and STDs infection status can be monitored and controlled. Moreover, we found that higher subjective support scores indicate better awareness of AIDS infection. Considering the characteristic of subjective support, it may suggest that support from families, friends, neighborhoods and colleagues play an important part in self-monitoring of AIDS. Additionally, higher scores in utility of support correlate with less possibility of being diagnosed with STDs, suggesting that individual utilization of available social support facilitates the controlling and prevention of STDs infection.

There are certain limitations in this study. First, because we only recruited migrant women who attended medical check-ups, our analysis is susceptible to bias considering that those who did not attend medical care may be worse off in terms of social support and related outcomes. Second, due to the cross-sectional nature of the study, no causality can be determined; and as such, the findings of this study should be applied with caution. Also, it is important to identify possible influencing factors other than those investigated in this study, which may impact social support and social network as well as migrant women's mental health. Future studies can include factors such as personal willingness of adaptation, interpersonal relationship, and perceived discrimination and their association with social support level. This can help further increase the understanding of the effects of the socio-psychological factors on social support. Finally, pre-migration factors were not investigated in this study, and these could also have had an influence on immigrants' adjustments and development of social support condition. Additionally, in the analysis of AIDS infection status, there were only 6 people in migrant women group reported knowing themselves to be infected, which may impact the validity of analysis. Despite these limitations, we believe our study also has several strengths. This study is a pioneering analysis of the marriage-based migrant women who plays a critical role in HIV/AIDS prevalence in their ingoing ground. We picked up representative cities to sketch the social support condition and minimized the cost of the study. Additionally, we confirmed the relation of HIV/AIDS infection to social support condition in this group.

\section{Conclusions}

This study outlines the social support condition as pioneering analysis of the special group of married migrant women who play an important role in HIV/AIDS prevalence in Shandong province, China. Several factors, namely education level, family average income, occupation, relationship with spouse, the number of children with husband, claimed reason of marrying in Shandong, were identified to influence various dimensions of social support. This study also confirmed that higher level of social support is related with better awareness of AIDS and STDs infection among this group. This permits better interference of health professionals and administrators, helping Chinese migrant women improve their social support and health status, thus benefiting the control and prevention of HIV/AIDS. Further research should explore practical ways to provide social and mental support to this special group.

\section{Abbreviations}

AIDS: Acquired Immune Deficiency Syndrome; HIV: Human

Immunodeficiency Virus; STD: Sexually Transmitted Disease; ANOVA: Analysis of Variance.

\section{Competing interests}

The authors declare that they have no competing interests.

\section{Author's contributions}

DK, YS and WM conceived and designed the study. YS and TH performed the study. WM and YS analyzed the data. WM, YS and GM contribute to writing the manuscript. WM, DK, CW, GM, WM critically revised the paper. All authors read and approved the final manuscript.

\section{Acknowledgments}

This study was supported by Humanity and Social Science Youth foundation of Ministry of Education of China (10YJCZH109). We would like to acknowledge the staff of Linyi Center for Disease Control and Prevention, Weifang Center for Disease Control and Prevention, and Yantai Center for Disease Control and Prevention for their help.

\section{Author details}

${ }^{1}$ Department of Epidemiology and Health Statistics, School of Public Health, Shandong University, 44 West Wenhua Road, Jinan, Shandong Province 250012, China. ${ }^{2}$ Institute of AIDS Control and Prevention, Shandong Center for Disease Control and Prevention, Jinan, China. ${ }^{3}$ Nosocomial Infection Control Section, Zhengzhou No.7 People's Hospital, Zhengzhou, China. ${ }^{4}$ Department of Epidemiology and Biostatistics, The University of Californian, San Francisco School of Medicine, San Francisco, USA.

Received: 25 May 2015 Accepted: 17 November 2015

Published online: 24 November 2015

\section{References}

1. Joint United Nations Programme on HIV/AIDS and International Organization for Migration. Population mobility and AIDS. Geneva, Switzerland: Joint United Nations Programme on HIV/AIDS; 2001.

2. Krilov LR. Emerging infectious disease issues in international adoptions: severe acute respiratory syndrome (SARS), avian influenza and measles. Curr Opin Infect Dis. 2004;17:391-5.

3. Jia ZW, Tang GY, Jin Z, Dye C, Vlas SJ, Li XW, et al. Modeling the impact of immigration on the epidemiology of tuberculosis. Theor Popul Biol. 2008;73:437-48.

4. Naresh R, Tripathi A, Sharma D. Modelling and analysis of the spread of AIDS epidemic with immigration of HIV infectives. Math Comput Model. 2009;49:880-92.

5. Qiu PY, Yang Y, Wu F, Cao X, Zhao SN, Ma X. Progress and enlightenment of home and abroad researches on mental health of mobile population [in Chinese]. Chin Mental Health J. 2010;1:64-8. 
6. Xu P, Wang WJ, Chen X, Luan RS, Liu W, Lin P, et al. Analysis of the prevention and control of AIDS on flowing population in parts of China [in Chinese]. Chin J Health Policy. 2009;2:48-52.

7. Yimer S, Bjune G, Alene G. Diagnostic and treatment delay among pulmonary tuberculosis patients in Ethiopia: a cross sectional study. BMC Infect Dis. 2005;5:112.

8. MOHC U, WHO. Estimated AIDS epidemic in China in 2011 [in Chinese]. Chin J AIDS\&STD. 2012;1:1-5.

9. LV CX, Fu JH, Zhang XF, Dong L, Su SL, Qian YS. Analysis of HIV epidemic situation and immigrant population in Shandong [in Chinese]. Modern Preventive Med. 2011;21:4351-2.

10. Fu JH, Zhang QH, Lv F, Liu XZ, Zhang XF. HIV-related demographic characteristics of migrant women in a rural district of Shandong province [in Chinese]. Chin J AIDS\&STD. 2006;5:418-20.

11. Su SL, Kang DM, Li JZ, Fu JH, Wang TJ, Zhang SY, et al. Investigation on HIV/ AIDS and related disease infection status among immigrant women in rural areas of Shandong province [in Chinese]. Mod Prev Med. 2011;8:1545-6.

12. Chen ZQ, Liu QL. Analysis of HIV/AIDS sentinel surveillance in different population in Heze [in Chinese]. Mod Prev Med. 2007;14:2730-1.

13. Yan J. Examination result and epidemiology analysis of different crowd HIV serology in a city 2007-2010 year [in Chinese]. Guide Chin Med. 2011;24:182-3.

14. Ward C, Kennedy A. Psychological and socio-cultural adjustment during cross-cultural transitions: A comparison of secondary students at home and abroad. Int J Psychol. 1993:28:129-47.

15. Jasinskaja-Lahti I, Liebkind K, Horenczyk G, Schmitz P. The interactive nature of acculturation: perceived discrimination, acculturation attitudes and stress among young ethnic repatriates in Finland, Israel and Germany. Int J Intercult Relat. 2003:27:79-97.

16. Ward C, Bochner S, Furnham A. The psychology of culture shock. East Sussex: Routledge; 2001.

17. Safdar SF, Lay CH. The Relations of Immigrant-Specific and ImmigrantNonspecific Daily Hassles to Distress Controlling for Psychological Adjustment and Cultural Competence. J Appl Soc Psychol. 2003;33:299-320.

18. Reber AS: The Penguin dictionary of psychology. London: Penguin Books 1995.

19. Chakrabarti R. Therapeutic networks of pregnancy care: Bengali immigrant women in New York City. Soc Sci Med. 2010;71:362-9.

20. Reitmanova S, Gustafson DL. "They can"t understand it": maternity health and care needs of immigrant Muslim women in St. John"s, Newfoundland. Matern Child Health J. 2008;12:101-11.

21. Li JZ, Kang DM, Zhang SY, Huang T, Su SL, Fu JH. HIV-related disease infection status and mental health of migrant women in Ju [in Chinese] Mod Prev Med. 2010;13:2469-71.

22. Wang $X$. A survey of HIV infections among non-native women in rural areas in certain city, Shandong province [in Chinese]. Chin J Dis Control Prev. 2006;6:620-1.

23. Lu CF, Jia CX, Zhang JY, Wang XX, Wang DF, Liu LY. Reliability and validity of social support rating scale in rural suicides [in Chinese]. Chin Mental Health J. 2011;3:218-22.

24. Xiao SY. The theoretical base and research application of social support rating scale [in Chinese]. J Clin Psychiatry. 1994;2:98-100.

25. Hwang SS, Xi J, Cao Y, Feng X, Qiao X. Anticipation of migration and psychological stress and the Three Gorges Dam project, China. Soc Sci Med. 2007;65:1012-24

26. Xi J, Hwang S-S. Unmet expectations and symptoms of depression among the Three Gorges Project resettlers. Soc Sci Res. 2011;40:245-56.

27. Teng L, Robertson Blackmore E, Stewart DE. Healthcare worker's perceptions of barriers to care by immigrant women with postpartum depression: an exploratory qualitative study. Arch Womens Ment Health. 2007;10:93-101.

28. Lu MC, Lin YG, Prietto NM, Garite TJ. Elimination of public funding of prenatal care for undocumented immigrants in California: a cost/benefit analysis. Am J Obstet Gynecol. 2000;182:233-9.

29. Higginbottom GM, Hadziabdic E, Yohani S, Paton P. Immigrant women's experience of maternity services in Canada: a meta-ethnography. Midwifery. 2014:30:544-59.

30. Gagnon AJ, Dougherty G, Wahoush O, Saucier JF, Dennis CL, Stanger E, et al. International migration to Canada: the post-birth health of mothers and infants by immigration class. Soc Sci Med. 2013;76:197-207.
31. Liu Y, Lin CZ, Huang HJ, Yin Q, Zhang ZR. Influence of personality characteristic and social support on mental health of flowing population [in Chinese]. Chin J Public Health. 2011:4:421-3.

32. Yan Z, Peng AH, Zhang LY. Population sociological factors of social support condition of rural flowing population [in Chinese]. Mod Prev Med. 2008;18:3563-6.

33. Dalgard OS, Thapa SB. Immigration, social integration and mental health in Norway, with focus on gender differences. Clin Pract Epidemiol Ment Health. 2007;3:24.

34. Tonsing KN. Predictors of psychological adaptation of South Asian immigrants in Hong Kong. Int J Intercult Relat. 2013;37:238-48.

35. Song Y, Kang D, Wang G, Wei C, Tao X, Huang T, et al. HIV/AIDS-related Knowledge and Behaviors Among Rural Married Migrant Women in Shandong Province, China: A Comparison Study. Arch Sex Behav. 2015:44:367-74.

\section{Submit your next manuscript to BioMed Central and we will help you at every step:}

- We accept pre-submission inquiries

- Our selector tool helps you to find the most relevant journal

- We provide round the clock customer support

- Convenient online submission

- Thorough peer review

- Inclusion in PubMed and all major indexing services

- Maximum visibility for your research

Submit your manuscript at www biomedcentral com/submit 